\title{
Heberto Padilla, Julio Cortázar y Mario Vargas Llosa: tres diferentes traducciones del desencanto
}

\section{Heberto Padilla, Julio Cortázar y Mario Vargas Llosa: Three Different Translations of Disenchantment}

\author{
José Arreola*
}

Resumen: el artículo analiza la proyección de los debates con respecto al papel de los artistas e intelectuales tras el triunfo de la Revolución cubana y el caso Padilla en tres novelas: En mi jardín pastan los héroes, de Heberto Padilla; Libro de Manuel, de Julio Cortázar y La guerra del fin del mundo, de Mario Vargas Llosa. El objetivo es examinar las diferencias entre las visiones artísticas de los autores acerca del desencanto políitico e intelectual surgido en torno a la Cuba del quinquenio gris a través del diálogo entre la ficción narrativa y el contexto histórico del momento. A partir de dicho análisis, puede concluirse que el desencanto político es una apropiación creativa generadora de reflexiones artísticas e intelectuales abordadas por los autores en las tres obras mencionadas.

Palabras Clave: Desencanto; Revolución cubana; Caso Padilla.

ABSTRACT: The article analyzes the projection of debates regarding the role of artists and intellectuals after the triumph of the Cuban Revolution and the Padilla case in three novels: En mi jardín pastan los héroes, by Heberto Padilla; El libro de Manuel, by Julio Cortázar and La guerra del fin del mundo, by Mario Vargas Llosa. The objective is to examine the differences between the authors artistic visions of the political and intellectual disenchantment that arose around Cuba in the gray quinquennium through the dialogue between narrative fiction and the historical context of the moment. From this analysis, it can be concluded that political disenchantment is a creative appropriation generating artistic and intellectual reflections addressed by the authors in the three works mentioned.

KEYWORDS: Disenchantment; Cuban Revolution; Padilla Case.

Recibido: 6 de abril de 2020

Aceptado: 26 de agosto de 2020

Tecnológico Universitario del Valle de Chalco, México (grafdar@yahoo.com). 


\section{INTRODUCCIÓN}

En 1989, en una breve entrevista realizada por Cecilia Ceriant publicada en El País, Heberto Padilla declaró: "Pensaba que todo el que se decepcionaba de una revolución era un renegado político. Odiaba los libros de los renegados porque pienso que la épica humana es siempre positiva, no puedes hacer una épica de la desilusión. Luego viene la lírica, que es huir de la épica. La lírica es la reflexión solitaria, el desencanto" (Ceriant 1989). Las palabras del cubano revelan una característica de su poesía, pero también el hecho de que lo sucedido alrededor de su figura, entre los años 1968 y 1971, puede pensarse como el inicio del desencanto político desde el ámbito literario en términos de la ruptura de una relación de apertura, debate y diálogo entre la dirigencia de la Revolución cubana y los intelectuales latinoamericanos durante las décadas de 1960 y 1970 (Martínez 2006). ${ }^{1}$ Dentro de la ciudad letrada latinoamericana la visión predominante hasta los albores de la década de 1970 era, a grandes rasgos, que el escritor no podía olvidarse de su responsabilidad política militante y que su quehacer literario necesitaba contribuir al cambio de los sistemas políticos padecidos en América Latina (Pereira 1995: 20). De tal suerte, Cuba aparecía como un país faro: la Revolución socialista "de los humildes, con los humildes y para los humildes" (Castro 1961) marcaba la ruta a seguir. Sin embargo, con el encarcelamiento de Heberto Padilla, cuyo caso tuvo un primer episodio en 1968 tras la publicación del poemario Fuera del juego, esa idea quedó en entredicho: para una parte de los intelectuales latinoamericanos tampoco la Cuba socialista era la sociedad

1 Existen algunos estudios sobre el desencanto que se centran en escritores de Ecuador, Brasil y Argentina. Shopia Yáñez realiza un análisis de tres novelas ecuatorianas. Desde su perspectiva el desencanto aparece como "un fenómeno social y cultural" (Yáñez 1997). Sobre Brasil y Argentina se encuentra el estudio realizado por Florencia Garramuño en el que señala que "Desencanto sugiere muerte o inacción sino desconfianza, desilusión, desengaño, y hasta desesperanza o desaliento. No aboga por ningún nuevo paradigma, ni celebra una utopía eufórica: simplemente constata que ante la modernización que continúa su ritmo irrefrenable, la cultura parece continuar en aquélla ya no un motivo de celebración sino una profunda desilusión y desengaño" (Garramuño 2009: 56). 
a la que aspiraban. De ese modo, la esperanza de una relación cordial entre la intelectualidad latinoamericana y la dirigencia revolucionaria cubana se desdibujó. Si la literatura latinoamericana de la década de 1960 estuvo signada por una vivacidad expresada en el decidido apoyo de los escritores e intelectuales a la Revolución cubana, que se conjugó con el fenómeno editorial del boom, el arresto de Heberto Padilla en 1971 rompió esa suerte de hegemonía cultural marcada por una agenda de izquierda (Franco 2003). José Donoso se refiere a ello en su Historia personal del boom: "Creo que si en algo tuvo unidad casi completa el boom -aceptando la variedad de matices-, fue en la fe primera en la causa de la revolución cubana; creo que la desilusión producida por el caso Padilla la desbarató, y desbarató la unidad del boom" (Donoso 1987: 47).

El caso Padilla inauguró una nueva perspectiva en la literatura: la del desencanto político-intelectual que supuso una pérdida de esperanza en el proyecto que representaba hasta esos años la Revolución socialista cubana. Ese resquebrajamiento produjo una revisión en el debate sobre el papel del escritor-intelectual en la ciudad letrada de América Latina. En varios escritores hubo un retorno a la idea del intelectual como el implacable crítico de la sociedad y, especialmente, el regreso a la concepción del arte en sí, de la literatura sin más. ${ }^{2}$ Intelectuales de la talla de Ángel Rama también marcaron un distanciamiento con Cuba, así se lee en las notas de su diario personal al referirse a un reportaje realizado por Luis Crespo sobre Roberto Fernández Retamar:

una incomodidad intelectual se agrega cuando leo sus explicaciones sobre lo ocurrido en la cultura cubana [...] aquí no ha pasado nada, todo está

2 No deja, por eso, de ser sintomática la publicación del volumen titulado América Latina en su literatura que en buena medida rescata y refleja los distintos puntos de vista y matices sobre la noción de compromiso del escritor ya en los primeros años de la década de 1970. En ese volumen, Emir Rodríguez Monegal afirma: "lo que caracteriza incluso a una literatura como la cubana a partir de 1959 es la insistencia de sus mejores escritores en no dejarse regimentar [...]. Pero los creadores más profundos e independientes, cualesquiera que sean su credo y su filiación como hombres, han luchado y continúan luchando por una literatura cuyo máximo compromiso sea con la propia literatura" (Monegal 1972: 142). 
igual, continúa idéntica la producción, se premia en los concursos lo que es artísticamente válido, sin más, los escritores trabajan, los lectores leen, el socialismo es la bienaventuranza sin conflicto. Lo grave de este fingimiento diplomático es la falta de defensa beligerante, de acción esclarecedora y proselitista acerca de la vía que tomó la literatura y el arte en Cuba (Rama 2001: 44 y 45).

Las palabras de Rama manifiestan la preocupación y el desencanto de un intelectual de izquierda en esos momentos de polémica. Al considerar a los intelectuales de la Revolución cubana como incapaces de elaborar un discurso político ideológico coherente sobre el rumbo que el arte había tomado en la isla luego del encarcelamiento de Padilla, el uruguayo mostraba una desilusión bifurcada; por un camino, la desilusión hacia los propios intelectuales cubanos; por otro, el desencanto con el proceso revolucionario cubano en general (Rama 1984: 60-63). El caso Padilla coincide en la historia de América Latina con distintos reveses en el proyecto de Revolución continental: la muerte del Che Guevara en Bolivia en 1967, la masacre de Tlatelolco en México apenas un año después, los golpes de Estado y las dictaduras militares instauradas en buena parte del continente. A decir del cubano Jorge Fornet, todos estos sucesos ayudan a comprender por qué aparecen novelas que "narraban la frustración provocada por el fin de la utopía de la revolución continental". Fornet enlista algunas narraciones que desde el título mismo muestran su motivación: Teoría del desencanto (1985), del ecuatoriano Raúl Pérez Torres; Sin remedio (1984), del colombiano Antonio Caballero, y La desesperanza (1986), del chileno José Donoso (Fornet 2006: 59). Vale aclarar que el desencanto al que se hace referencia no se liga tanto a la idea de una Revolución "traicionada" -como la que tempranamente se dibujó en escritores de renombre como Guillermo Cabrera Infante-, y en cambio se acerca mucho más a la desesperanza y frustración artística representadas en el quinquenio gris cuyas repercusiones se hicieron sentir en el resto del campo literario e intelectual latinoamericano. Fue el mismo Jorge Fornet quien propuso el término de literatura del desencanto para caracterizar a una generación de escritores cubanos entre los que destaca Leonardo Padura. Su tesis central se basa en que los autores de dicha generación "sustentan su des- 
encanto en las insuficiencias y contradicciones de una revolución en la que creyeron o creen; los de la llamada novela 'anticastrista' parten de una supuesta traición, porque para sus autores la revolución realmente existente es, casi desde el principio, espuria e ilegítima" (Fornet 2006: 68). Es, para decirlo, en otros términos, un desencanto que puede considerarse, a pesar de todo, dentro de la Revolución. Desde su perspectiva, fue Heberto Padilla quien puso a circular entre los cubanos la noción de desencanto. El encarcelamiento del poeta hizo manifiesta, dentro y fuera de Cuba, la brecha que se abría entre una parte de la intelectualidad considerada de izquierda y la dirigencia cubana. Además, evidenció que se estaba modificando no solamente la relación con los intelectuales sino también el concepto mismo de cultura (Fornet 2013). Si bien la generación a la que el crítico cubano enmarca en la literatura del desencanto se encuentra conformada por escritores cubanos que publican ya maduramente en la década de 1990, resulta significativo el obligado reparo en Padilla como el responsable de poner en circulación el desencanto en cuanto idea literaria y política. En su autoconfesión ante la Unión Nacional de Escritores y Artistas de Cuba (UNEAC), refiriéndose a Fuera del Juego, Padilla señaló "Y yo inauguré -y esto es una triste prioridad-, yo inauguré el resentimiento, la amargura, el pesimismo [...] yo siempre me he inspirado en el desencanto, mi desencanto ha sido el centro de todo mi entusiasmo [...]. Es decir, el motor de mi poesía ha sido el pesimismo, el escepticismo, el desencanto" (Padilla 1971). La insistencia sobre el desencanto no resultó casual porque, de ese modo, no solo se desmarcaba de una parte de los escritores del momento, sino que también abría una nueva noción para la propia literatura cubana y, por lo tanto, de todo lo que la Revolución significaba incluso "dentro" de ella misma. Heberto Padilla aparece así como el fundador del pesimismo revolucionario en la literatura: en un primer instante, menos del proyecto general de la Revolución cubana que de la posición prosoviética que ganó la batalla por el control del poder cultural. Por ello puede pensarse que si hubo un inicio de revisión profunda sobre el proyecto socialista cubano fue, sin duda, 1971. Esa inflexión representó, en estrictos términos, la primera crisis ideológica, cultural y política del socialismo a la cubana, así como una nueva relación de los intelectuales 
cubanos y latinoamericanos con el proyecto socialista de la isla. En ese sentido, el presente texto realiza un recorrido por tres novelas que, desde el espacio estético, proyectaron importantes reflexiones en torno al papel de la literatura y el intelectual en un contexto cultural como el que se ha descrito: En mi jardín pastan los héroes (1981), de Heberto Padilla; Libro de Manuel (1973), de Julio Cortázar y La guerra del fin del mundo (1981), de Mario Vargas Llosa.

\section{EN MI JARDÍN PASTAN LOS HÉROES \\ O LA CONSOLIDACIÓN NARRATIVA DEL DESENCANTO}

Fuera del juego inicia con un poema titulado "En tiempos difíciles", los primeros versos dicen: "A aquel hombre le pidieron su tiempo/ para que lo juntara al tiempo de la Historia" y en los versos posteriores se lee que a ese hombre le piden los ojos, las manos, la lengua, las piernas, en una sucesión que el sujeto lírico remata así: "Y finalmente le rogaron/ que, por favor, echase a andar/ porque en tiempos difíciles/ esta es, sin duda, la prueba decisiva" (Padilla 1968). El poemario tiene un sello de pesimismo, de escepticismo y crítica a las posiciones dogmáticas que crecían en el proceso revolucionario cubano. ${ }^{3}$ La declaración de la UNEAC, incluida al publicarse el libro, se refirió al autor y al poemario en los siguientes términos:

el autor mantiene dos actitudes básicas: una criticista y otra ahistórica [...]. En estos textos se realiza una defensa del individualismo frente a las necesidades de una sociedad que construye el futuro [...]. Cuando Padilla expresa que se le arrancan sus órganos vitales y se le demanda que eche a andar, es la Revolución, exigente en los deberes colectivos quien desmembra al individuo y le pide que funcione socialmente [...]. Esta defensa del

3 Otro de los poemas, "Los poetas cubanos ya no sueñan", expresa "los poetas cubanos ya no sueñan/ (ni siquiera en la noche)/ Van a cerrar la puerta para escribir a solas/ cuando cruje, de pronto, la madera;/ el viento los empuja al garete;/ unas manos los cogen por los hombros,/ los voltean/ los ponen frente a otras caras/ (hundidas en pantanos, ardiendo en el napalm)/ y el mundo encima de sus bocas fluye/ y está obligado el ojo a ver, a ver, a ver" (Padilla 1968). 
aislamiento equivale a una resistencia a entregarse a objetivos comunes, además de ser una defensa de superadas concepciones de la ideología liberal burguesa (UNEAC 1968: 9).

Conviene, brevemente al menos, detenerse en algunas de las formulaciones presentes en la declaración. En primer lugar, resulta significativo el tono de agresividad hacia el poeta y su obra con el que se condenan, a decir del jurado, "actitudes criticistas" y "ahistóricas". Desde tal perspectiva, se adjetivaba a la crítica como un elemento no deseable en el proceso revolucionario y, además, desfasada del momento histórico inaugurado en 1959. En segundo lugar, el hecho de que se supeditara el punto de vista individual del poeta no solamente a la historia sino también a los "objetivos comunes" de una Revolución que, según tales formulaciones, había superado "concepciones de la ideología liberal burguesa". Y, por último, la formulación de juicios de carácter político para calificar una obra estética. Sea como fuere, la declaración marcaba el inicio de lo que tres años después se encumbraría como un nuevo ciclo en la hegemonía cultural de la Revolución cubana.

Meses antes de ser arrestado, Padilla fue entrevistado por Cristián Huneeus y señalaba que su poesía no era "'útil' en el sentido que habitualmente se entienda; tal vez se espere de la poesía cubana, como siempre se esperaba o se exigía de la poesía y de la literatura rusa, que reflejaran, más que la realidad que vivían, el proyecto de realidad por el que luchaban" (Hunneus 1971; las cursivas son mías). A la luz de la polémica cultural del momento, la formulación resultaba reveladora con respecto a su visión de lo que la poesía le significaba, es decir, una manifestación capaz de reflejar la realidad que se vivía ligada a la lírica o, en otras palabras, que su poesía era un canto a las dificultades en carne viva. Dicha visión se oponía, por lo tanto, a la concepción utilitaria de la literatura que debía reflejar no la realidad sino el proyecto de realidad que la Revolución representaba y que, además, se cimentaba en un discurso épico del socialismo cubano. Años más tarde, en La mala memoria, Heberto Padilla recordaría que muchas veces se había preguntado "¿Quién era yo realmente?, ¿Una suerte de esteta crepuscular que paseaba sus maltrechas esperanzas entre los aeropuer- 
tos del Este y del Oeste, entre mundos en pugna?, ¿qué bacer cuando ya no se cree?, ¿qué hacer con la vieja esperanza?" (Padilla 1989: 48) (las cursivas son mías). Desesperanza, desencanto, descreimiento fueron, de ese modo, componentes de la obra artística de aquel esteta viajero. Sin embargo, es hasta la escritura de En mi jardín pastan los héroes (1981) cuando el canto a la desesperanza y el desencanto hacia la Revolución estallan en todo su esplendor, reafirmándose como los cimientos de su quehacer literario. Según el autor, la novela fue escrita entre 1970 y 1980, es decir, el periodo en el que se convirtió en el centro de la controversia cultural, para después vivir en la marginación artística y, finalmente, abandonar la isla con destino a Estados Unidos.

En el prólogo a la novela, el escritor pinareño advierte que su narración, debido a "la grotesca parodia de cuanto me ocurrió en Cuba", tuvo que remitirse, casi de manera inevitable, "a mi propia vida" (Padilla 1981: 23). El reparo del autor no es menor, porque entonces la novela pasa a dar testimonio, utilizando el recurso de la ficción, de sus vivencias, dolores y preocupaciones. En la obra existe una proyección del propio Padilla, matizada a partir de las herramientas literarias. El prólogo no deja lugar a dudas de sus inquietudes:

Son inconclusos los destinos de cada uno de estos personajes, las situaciones en que están envueltos, porque inconcluso y fragmentario es todo cuanto se escribe en una atmósfera política de asfixia, cuando las páginas de un libro deben ser escondidas y el "tiempo absoluto de la literatura" de que hablan los críticos y de donde afirman aparece la genuina calidad, se hace secundario y lo que prevalece es el peso, casi furioso, del mensaje. Los libros que se escriben en el socialismo son generalmente imperfectos, la estética en boga o clandestina de estos países los hace segregar siempre desesperación o neurosis (Padilla 1981: 23; las cursivas son del autor).

Las palabras de Padilla son una muestra del desencanto y la desesperanza encarnados en él; sin habérselo propuesto, realizó una evaluación general de lo que sus obras representaban. Si todo aquello que se escribía en el socialismo resultaba imperfecto, entonces sus textos no escapaban a dicha imperfección; incluso los anteriores a En mi jardín pastan los béroes, puede apreciarse una paradoja: él se consideraba más un autor 
de lo lírico ligado a la desesperanza, es decir, a la realidad con todas sus contradicciones, más que a la proyección de una posible vida perfecta; si esa realidad tenía como resultado que los autores arrojaran "siempre desesperación o neurosis" lo importante no estribaba en el mensaje sino en la calidad literaria con la que estas se expresaban, se viviera o no en un clima asfixiante. Para decirlo de otro modo, los autores tenían el derecho a la desesperanza así se tratara de la sociedad más perfecta y feliz. De hecho, en el mismo prólogo relató parte de una conversación con el oficial Álvarez, uno de sus carcelarios, a quien le señaló que al escribir la novela no tuvo más propósito que "reflejar algunos caracteres y conflictos que sólo surgen en un proceso revolucionario" (Padilla 1981: 15). La Revolución aparece así, por una parte, como la responsable de los conflictos y, por otra, como la simiente de las inquietudes literarias del autor.

En la novela, el personaje central es un escritor -Gregorio Suárezque a su vez narra la vida de otro escritor -Julio- escéptico, confundido, atrapado entre la idea de su arte y la subsistencia en el sistema político cubano; entre la literatura y la política. Julio es una suerte de alter ego de Padilla: traductor, conocedor de la diplomacia cubana, con amigos intelectuales del extranjero como Günter, que será expulsado de Cuba. Humberto, el hermano de Julio, es un funcionario del régimen revolucionario. Ambos debaten sobre el futuro del socialismo en Cuba y a decir de Julio, Humberto lo considera "con indulgencia, como escéptico. Quería, desde luego, llamarlo por lo menos pesimista" (Padilla 1981: 117). El siguiente es uno de los diálogos entre ellos:

-Mira, Julio, este país ha cambiado y acéptalo. Para bien o para mal. Acéptalo, o ya sabes. No hay alternativas.

-Ni siquiera para una inteligencia crítica.

-Ni siquiera.

-Entonces esto es una mierda.

-iY qué?

-Esto es una mierda más -gritó Julio-. Si esta situación no admite una actitud crítica, es una reverenda mierda. ¿Sí o no?

-No -repuso Humberto serenamente-. A pesar de todo, no es así. Porque este país está plagado de inteligencias críticas cuya única virtud es ser una inteligencia crítica. Y eso sí que es una reverenda mierda (Padilla 1981: 69). 
El fragmento revela el escepticismo de Humberto: el cambio político que representaba el triunfo del ejército rebelde no se asocia, necesariamente, con un cambio "bueno", sino que puede ser "malo". Si es bueno o no, el hecho se reduce, para Humberto, en que no existe más alternativa que apoyar el proyecto revolucionario. Para Julio, en cambio, la mayor preocupación se encontraba en la existencia necesaria de una "inteligencia crítica". Por lo tanto, si la Revolución no admitía "una actitud crítica" no era más que una reverenda mierda. La respuesta de Humberto es contundente pues donde Julio cree hallar una ventaja, su hermano señala el mayor de los defectos: ser una inteligencia crítica como única virtud es lo que esas inteligencias críticas deberían considerar como una "reverenda mierda". En el fondo, la polémica establecida entre Humberto y Julio es no solo una profunda reflexión intelectual sino también una construcción literaria del debate cultural y político de la época en la que la narración se sitúa. Es decir, los años que van de 1961 a 1971, entre la década de apertura y debates y el giro en las políticas culturales de la isla.

En el relato, Luisa -la compañera sentimental de Julio, que es aquejada por una fuerte depresión y sufre de crisis nerviosas- también plasma su incredulidad acerca de la viabilidad del proyecto revolucionario. Aunque ella comulga mucho más que su pareja con el proceso, conmina a Julio y a Humberto a no hablar de política y Revolución o de lo contrario "acabarán en un manicomio" (Padilla 1981: 67). La formulación, dentro del discurso narrativo de la historia, no es casual y abona al clima de incomprensión: todos los que hablan de política, de Revolución y socialismo, terminan locos. En otro pasaje, se describe lo que bien puede entenderse como una discusión entre un funcionario revolucionario y un intelectual desencantado:

Entonces Julio gritó que él no entendía absolutamente nada [ . . . ]. Y Humberto igualmente que una revolución tenía sus leyes implacables y que esas leyes establecían su propia moral, por muy virulenta y desagradable que resultase y le pidió que estudiara Historia y Julio le gritó que la Historia era una pura mierda y se enfrascaron en un diálogo de sordos agitando los brazos (Padilla 1981: 72). 
El fragmento revela la visión del propio Padilla: en una Revolución como la cubana no había diálogo ni debate, sino insultos. Desde esa perspectiva, "las leyes implacables" regían el actuar de los individuos y la "Historia" los dominaba y minimizaba, aunque esta fuese "pura mierda". Si Luisa creía que hablar de política y Revolución terminaba por volver locas a las personas, hablar sin escuchar en un "diálogo de sordos" no era sino una manifestación más de locura. En otro momento, Julio realiza una reflexión sobre los turistas "revolucionarios" que viajan a Cuba:

Mientras más elementos de barbarie exhiban estas revoluciones distantes, tanto mayor el número de simpatizantes y adeptos. Pro chinos, pro cubanos! Aprobando todas las monstruosidades que una mentalidad europea considera inadmisibles en sus respectivos países. Éste era el punto más neto de ese espíritu decadente que mezcla la tonta ingenuidad con el más abyecto nihilismo, todo ello bajo una especie de comprensión. Pero él sabía, desde hacía muchos años, que esta comprensión no es sino justificación, y toda justificación es una forma de complicidad. Desconfiaba de la ilusión, de las bellas almas entusiastas que aterrizan en los precarios países del Tercer Mundo y regresan después a las ciudades confortables con cuatrocientas páginas o más sobre un mundo que, no sólo ignoran, sino que falsifican en nombre de la más grosera esperanza (Padilla 1981: 115).

El fragmento muestra el descontento de Julio, primeramente con los turistas revolucionarios, pero también con el proceso: solamente es valedero porque contiene elementos de barbarie y a mayor barbarie, mayor simpatía. Tal simpatía impedía ver las monstruosidades que, además, terminaban en el espacio de la "comprensión" o, en otros términos, de complicidad con lo inadmisible. En ese sentido, las palabras del personaje funcionan como parte de la atmósfera de "grosera esperanza" dibujada por el autor: la Revolución pasa, entonces, a ser pura mierda, un manicomio y una pantomima en la que se simula el diálogo. Por esa razón, Julio concluye que "una revolución no se reduce a las efusiones de los comienzos, los planes, los sueños, los viejos anhelos de redención y justicia social que quieren realizarse, tiene también su lado oscuro, difícil, casi sucio: represión, vigilancia policial, sospecha, juicios sumarios, fusilamientos. No había opciones. La totalidad lo incluía todo y él era parte de ella" (Pa- 
dilla 1981: 185) (las cursivas son mías). En la historia, el escritor establece una relación con Ona, una periodista noruega que buscaba conocer Cuba a profundidad. Es descubierto por Luisa, quien no duda en decirle que más valía a todos los intelectuales "arrancarles la cabeza", lo que deriva en otra disquisición de Julio:

el hecho de que recurriese al argumento político para reprocharle su conducta con Ona, le daba la medida de los extremos a los que habían llegado las tensiones políticas del país: lo presidían todo, entraban en cada vida, se metían en las bocas y el subconsciente de la gente. Ni una ruptura matrimonial escapaba a su imperio, la acusación virulenta, inapelable como prejuicio que estalla cuando menos se espera; el último argumento de todos los amigos, el solo pretexto que legitimaba rupturas y desavenencias. Luisa también se instalaba en él, lo manejaba con la misma destreza; se salvaba echándoselo en cara; se exorcizaba y se transformaba al acusarlo de enemigo de la Revolución. ¿A cuántos no había visto acogerse a estas palabras en los últimos años? No marcaban límite de convicciones, ni evolución de la conciencia política; era señal de acatamiento de resignación. Adaptarse al sistema era partir en dos la vida, lograr un salvoconducto para el porvenir (Padilla 1981: 264).

En suma, los cuestionamientos de Julio son, en gran parte, las preocupaciones que albergaba Padilla: chasta dónde podía existir una separación entre la política y el intelectual?, chasta dónde la Revolución cubana permitía la libertad creadora?, ¿quiénes eran los enemigos de la Revolución?, ¿quiénes los enemigos de la libertad artística? Como se ha señalado líneas arriba, la política cultural cubana se endureció y los artistas advirtieron el peligro sobre este fenómeno. El escepticismo de Padilla y el desencanto que mostraba hacia el proceso revolucionario estuvo fundamentado en ese endurecimiento, en el rumbo que el primer proyecto de izquierda socialista en América Latina estaba tomando. Sus creaciones artísticas fueron la expresión de su desencanto y pérdida de horizonte. De ese modo, Heberto Padilla cuestionaba al socialismo que vivió en carne propia: aquel de la grosera esperanza, el de la locura, la cárcel y el de la asfixia artística. 
En 1969, el semanario uruguayo Marcha publicó una serie de artículos en los que Óscar Collazos, Julio Cortázar y Mario Vargas Llosa abordaron algunos temas sobre la novelística del momento y el papel de los escritores en su calidad de artistas e intelectuales latinoamericanos. Óscar Collazos aseguraba que Julio Cortázar era uno de esos autores en cuyas obras se asomaba "el olvido de la realidad, el desprecio de toda referencia concreta a partir de la cual se inicia la gestación del producto literario" (Collazos 1970: 14). Como respuesta, el argentino planteó la idea de que en el contexto literario de Latinoamérica se necesitaba, más que nunca, a los Che Guevara del lenguaje, es decir a "los revolucionarios de la literatura más que los literatos de la revolución" (Cortázar 1970: 76; las cursivas son del autor). Como bien ha señalado Claudia Gilman, la polémica se desarrolló en un momento en el que a los intelectuales y a sus producciones literarias se les concedía una gran importancia política, misma que estuvo acompañada "de una interrogación permanente sobre su valor o disvalor social y por la intensa voluntad programática de crear un arte político y revolucionario" (Gilman 2003: 29). De ese modo, una postura política se trasladaba también al espacio de la creación estética o, más todavía, una obra artística pasaba a medirse con el rasero de los posicionamientos políticos. Es preciso señalar que durante el caso Padilla, Julio Cortázar tuvo una actitud conciliatoria con las partes en pugna, y que su postura hacia Cuba fue siempre de una solidaridad crítica, sin sumisión u obediencia ciega. "Policrítica a la hora de los chacales", publicado por Casa de las Américas en el número 67 de julio-agosto de 1971, es la mejor muestra de su posición ante el arresto del poeta y los acontecimientos suscitados alrededor de tal evento. Refiriéndose al texto del argentino, Jorge Fornet anota que "Era su respuesta al callejón sin salida en que se hallaban sus relaciones con La Habana, y específicamente con la Casa de las Américas. Fue su diatriba, en la que reunió la cuota de virulencia que necesitaba descargar" (Fornet 2013: 202). 
Apenas dos años después del caso Padilla, en 1973, se publica Libro de Manuel, libro de Cortázar al que, según sus propias palabras, "los propugnadores de la realidad en la literatura lo van a encontrar más bien fantástico mientras que los encaramados en la literatura de ficción deplorarán su deliberado contubernio con la historia de nuestros días" (Cortázar 2004: 7). La observación del argentino se inserta así en el debate literario e intelectual de la época; debate del que, como se ha señalado líneas antes, él mismo fue partícipe. A diferencia de Heberto Padilla, el desencanto de Cortázar no se traduce como una pérdida de esperanza en los proyectos de izquierda, sino en una constante crítica a los excesos y prohibiciones que, en nombre de dichos proyectos, se cometían. Además, en el argentino se encuentra una inquietud especial: la dicotomía entre el escritor que cuando hacía literatura solamente hacía literatura y el militante revolucionario que cuando hacía política solamente hacía política (González 1978: 124). No obstante, como anota Jaume Peris Blanes, para Cortázar Libro de Manuel supuso "el resultado de la negociación entre la poética neovanguardista de sus anteriores novelas y las poéticas documentales y testimoniales que estaban transformando el campo literario latinoamericano en esos años" (Peris Blanes 2012: 99).

Libro de Mamuel plantea, por una parte, el desgarro de la insalvable situación cortazariana entre el intelectual y el militante político; por otra, el desencanto hacia esa concepción rígida y poco lúdica de un sector de la izquierda latinoamericana que concebía la creación artística solo en función de "utilidad" al servicio del pueblo y la Revolución. A Cortázar, como afirma José Miguel Oviedo, lo contagió "el demonio de la política y decidió purgar su previa indiferencia con una activa militancia que irritó a muchos" (Oviedo 2001: 161), pero ello no impidió que se afirmara, antes que nada, como un intelectual comprometido con su quehacer artístico y que a través de su ejercicio literario pudiera plantear las críticas que creyó indispensables. Libro de Manuel narra la historia de la Joda, un grupo de exiliados latinoamericanos en París que preparan el secuestro de altos funcionarios para canjearlos por la libertad de militantes políticos en prisión. Asimismo, relata cómo, de manera colectiva, los integrantes de la Joda componen un libro hecho de recortes de noticias, artículos 
periodísticos y panfletos para el pequeño Manuel, con la idea de que este pueda darse cuenta en el futuro de la realidad vivida por los pueblos de Latinoamérica. La Joda realiza también pequeñas acciones que van desde boicotear las cajas de los fósforos a comer de pie en un restaurante para desestabilizar el correr cotidiano de la vida. Hay, por ejemplo, una escena en la que Gómez, uno de los integrantes del grupo, se atreve a romper la regla de comer sentado y explica su postura en una clara alusión al año 1968: "Si yo como de pie es porque vivo de pie desde el mes de mayo" y luego de que la mesera armara un "quilombo" por tal espectáculo, Gómez decide comer sentado, no sin antes aclarar al resto de los comensales lo siguiente: "Lo hago por mi prójimo, y espero que mi prójimo aprenda a vivir de pie" (Cortázar 2004: 75). Tales microagitaciones contrastan con las grandes acciones revolucionarias, pero para los militantes del grupo significan una manera de trastrocar la cotidianidad, de llamar la atención, de alterar el orden por más que Marcos las evaluara como "diversión entre una y otra llamada telefónica". Andrés, complemento y a la vez antítesis de Marcos - mientras él es un militante comprometido, con una buena dosis de dogmatismo y dureza, Andrés es intelectual, juguetón y crítico- es uno de los personajes que, junto a Lonstein, polemiza constantemente sobre el papel del arte y el intelectual en un proceso revolucionario. Según Lonstein, el más sarcástico del grupo, para Marcos "había toneladas como Andrés, anclados en el París o en el tango de su tiempo, en sus amores o sus estéticas y sus caquitas privadas, cultivando todavía una literatura llena de decoro y premios nacionales o municipales y becas Guggenheim" (Cortázar 2004: 84).

Cortázar proyecta a través de Andrés las preocupaciones de un intelectual que se debate entre ser el escritor comprometido y el esteta revolucionario. Por eso, es Andrés quien de forma más directa cuestiona a Marcos, el intachable militante comprometido hasta la médula con la Revolución:

¿Qué haría Marcos si los azares de la Joda lo llevaran a ser eso que las tabletas asirias llamaban jefe de hombres? Su idioma corriente es como su vida, una alianza de iconoclastia y creación, reflejo de lo revolucionario en- 
tendido antes de todo sistema; pero ya Vladimir Ilich, sin hablar de León Davidovich y más de este lado y este tiempo Fidel, vaya si vieron lo que va del dicho al hecho, de la calle al timón. Y sin embargo uno se pregunta el porqué de ese pasaje de un habla definida por la vida, como el babla de Marcos, a una vida definida por el babla, como los programas de gobierno y el innegable puritanismo que se guarece en las revoluciones. Preguntarle a Marcos alguna vez si va a olvidarse del carajo y de la concha de tu hermana en que caso de que le llegue la hora de mandar; mera analogía desde luego, no se trata de palabrotas sino de lo que late detrás, el dios de los cuerpos, el gran río caliente del amor, la erótica de una revolución que alguna vez tendrá que optar (ya no éstas sino las próximas, las que faltan, que son casi todas)por otra definición del hombre; porque en lo que llevamos visto el hombre nuevo suele tener cara de viejo (Cortázar 2004: 97 y 98 ) (las cursivas son mías).

Las palabras de Andrés tienen la marca del desencanto: un desencanto que, no obstante, potencia su actividad artística y lúdica, un desencanto que se rebela contra el lenguaje burocrático buscando, como buscan las revoluciones auténticas, "otra definición del hombre". La última formulación del fragmento citado no deja lugar a dudas del puente de polémica que Cortázar tiende mediante sus personajes. La idea del hombre nuevo fue desarrollada, desde un plano estético y filosófico, por el Che Guevara y se convirtió en un tópico de la Revolución cubana. Al mencionar que el hombre nuevo tiene más bien cara de viejo se marca, con ironía cortazariana, una crítica y una esperanza: que hasta ese momento el hombre nuevo tenga cara de viejo no significa que en el futuro el rostro no corresponda al concepto. A lo largo de la novela, hay un marcado contraste entre Andrés y Marcos, mientras este último opta por la rigidez, por la seriedad y lo políticamente correcto, el primero insiste en la necesidad de un debate de las formas, del arte como parte imprescindible de la Revolución. Libro de Manuel representa el cuestionamiento de un sistema, de un mundo que "sigue defendiendo rabiosamente sus fórmulas", pero sobre todo es la crítica de un intelectual de izquierda para sus pares, para la izquierda latinoamericana en general y para los dirigentes revolucionarios en particular. Hay, desde luego, un dejo de nostalgia y amargura en las cavilaciones de los personajes que pugnan al mismo tiempo por la libertad 
colectiva del ser humano y la libertad individual, pero eso no les impide la irreverencia y la crítica. Lonstein señala, refiriéndose a algunos miembros de la Joda que "son tecnócratas de la revolución y creen que la alegría, los hongos y mi portera no entran en la dialéctica de la Historia" (Cortázar 2004: 166). El señalamiento es relevante y en línea con la polémica de la época porque advierte un peligro latente: el del discurso tecnócrata, el de una Revolución burocrática que deja fuera de la "Historia" diferentes aspectos de la vida cotidiana como la alegría, el erotismo, los hongos o la portera de un edificio. En el fondo, se trata de una polémica acerca de lo que puede considerarse aceptable o no en un proceso revolucionario.

La novela de Cortázar es una constante transgresión a la idea de un intelectual apologético, sin mayores críticas o cuestionamientos a los procesos políticos. ${ }^{4}$ Es Lonstein el que se encarga de poner en entredicho la entrega de Andrés a una causa: "Pero vos, que pretendés ser el testigo de la Joda, vos mismo te echás atrás a la hora de la verdad, quiero decir de la paja, me estoy refiriendo al hombre de veras, lo que es y no lo que ven los otros del Capital para afuera" (Cortázar 2004: 256). La mención a El Capital no es fortuita, se trata de una crítica irónica al marxismo dogmático del momento que actuaba apegado a los manuales políticos y como si la obra de Carlos Marx se olvidara, precisamente, de la principal preocupación de este, es decir, del propio ser humano, "el hombre de veras". En otro momento de la narración, Andrés señala lo siguiente:

tanta novela donde a cambio de un relato más o menos chatón hay que pasar por conversaciones y argumentos y contrarréplicas sobre la alienación, el tercer mundo, la lucha armada o desarmada, el papel del intelectual y el colonialismo cuando todo eso es, 1) desconocido por el lector, y entonces

4 Margery A. Safir afirma: "Lo que corre a través del Libro de Manuel son, pues, niveles paralelos de transgresión. Existe la transgresión de organismos gubernativos que provoca y justifica la transgresión de los personajes de la novela. Las transgresiones gubernativas se presentan a través de una serie de recortes de periódicos; y esos mismos recortes que documentan la transgresión son ellos mismos una forma de transgresión puesto que física y visualmente violan el espacio novelístico, atacando al mismo tiempo el mundo ficticio con una violencia que es real y está presente" (Safir, 1983:248; las cursivas son de la autora). 
el lector es un pánfilo y se merece esa clase de novelas para que aprenda, qué tanto o 2) es perfectamente conocido y sobre todo encuadrado en una visión histórica cotidiana, por lo cual las novelas pueden darlo por sobreentendido y avanzar hacia tierras más propias, es decir menos didácticas (Cortázar 2004: 285) (las cursivas son mías).

Las palabras de Andrés tienen como base la crítica a la idea de un arte de la Revolución antes que el arte revolucionario. Es decir, un arte concebido "revolucionario" por su adhesión a una causa y no por su construcción estética; un arte al servicio de los procesos políticos pero capaz de tratar como un "pánfilo" a sus interlocutores; un arte cuya misión sería "educar" y no contribuir estéticamente a la superación de la alienación del ser humano. En el transcurso de la historia narrada por Cortázar, el secuestro de los funcionarios es descubierto y ocurre un enfrentamiento en el que Marcos y varios miembros más de la Joda son arrestados o ultimados. Andrés, que duda en acudir o no al chalet donde la Joda se ubica y mantiene secuestrados a los funcionarios, decide ir. Tras arribar al lugar se desata el tiroteo y piensa que ha sido su culpa, que por él la operación del canje ha fracasado. Aunque luego se sabrá que no se trató de que los policías lo siguieran hasta el lugar, sino de que este ya estaba rodeado, no deja de llamar la atención que el intelectual del grupo se culpe por el fracaso de la misión. Es él mismo quien habrá de concluir con la tarea de los recortes para Manuel. El gesto pudiera parecer banal y, sin embargo, es de trascendencia: culminará con la tarea más lúdica que la Joda se propuso. Es relevante porque el libro para el pequeño Manuel es la proyección de una obra muy al estilo de Cortázar: un collage que va de lo político al juego y viceversa. Es también trascendente porque, como ha señalado Jaume Peris Blanes, en la novela hay una experimentación novedosa para el propio autor, es decir, hacer que sus personajes leyeran y recortaran las noticias que Cortázar iba leyendo en aquel momento (Peris Blanes 2006).

En una charla con Lonstein, Andrés reflexiona sobre lo sucedido: "el juego se dio así, a ellos les pasaron cosas, y mí me pasaron otras que no tenían nada que ver, por ejemplo un mosca, pero mirá, al final bubo una especie de convergencia, por darle un nombre, ya que para otros fui yo el que les trajo la sarna" (Cortázar 2004: 413 y 414). Pero, además, como 
intelectual, el libro para el pequeño Manuel es testimonio material y simbólico de su participación en el proceso político.

La Joda es, al menos desde un plano figurado, la configuración de un grupo revolucionario por el que Cortázar pugnaba, uno en el que deben converger muchos puntos de vista. Así "Dentro del grupo de conspiradores, se dejan entrever diferentes personalidades, cuyas historias se entremezclan" (Maqueira 2002: 105). Por esa razón, por la pluralidad dentro de un proyecto de izquierda, caben personajes como Marcos, Gómez, Susana, Patricio, Heredia; por eso existen personajes como el "rabinito" Lonstein, onanista de pura cepa que, además, gusta de consumir hongos alucinógenos; por eso cabe también Andrés que, con sus discrepancias, sus cuestionamientos, asume como suyo lo que la Joda realiza. De tal suerte la Joda "desarrolla la voluntad de cada miembro que se integrará, desde su participación en intereses comunes, con la presencia de los demás" (Sosnowski 1994).

Libro de Manuel es testimonio de un Cortázar que, incluso cuando escribía literatura "política", ponía en primer plano la voluntad de forma, el hecho estético de la obra. De tal manera que el desencanto cortazariano está ubicado en la izquierda, desde la izquierda y para la izquierda. El compromiso de Cortázar no se encuentra sólo en el sentido político, no se constriñe a él, sino que en este halla la posibilidad de cambio sin que signifique renunciar a su condición humana y artística. Su razonamiento es más profundo porque, desde su perspectiva, el cambio real, el verdadero, se da en todas las esferas de la vida y, por eso mismo, la presencia de los intelectuales, de los artistas, no solo como "compañeros" sino como integrantes y partícipes de la Revolución es imprescindible.

\section{LA GUERRA DEL FIN DEL MUNDO}

O EL DEFINITIVO ADIÓS A LA REVOLUCIÓN

En 1967, al recibir el Premio Rómulo Gallegos, Mario Vargas Llosa pronunció un discurso que se conocería como "La literatura es fuego" en el que postuló que la razón de ser de un escritor era "la protesta, la contradicción y la crítica". A su entender, la hora de la liberación y la justicia social 
para los pueblos de Latinoamérica se acercaba y tenía un primer anuncio en Cuba. Aunque reconocía en el socialismo la vía para que esta parte del mundo se librara del horror y del anacronismo también señalaba lo siguiente "Pero cuando las injusticias sociales desaparezcan, de ningún modo habrá llegado para el escritor la hora del consentimiento, la subordinación o la complicidad oficial. Su misión seguirá, deberá seguir siendo la misma; cualquier transigencia en este dominio constituye, de parte del escritor, una traición" (Vargas Llosa 1967). Sus palabras mostraban cuáles eran sus prioridades, mismas que reiteró dos años después en aquella polémica sostenida con Óscar Collazos al señalar que, aunque el colombiano no estuviera de acuerdo con su postura, la literatura era siempre "subversiva" (Vargas Llosa 1970: 87). Los planteamientos del peruano se encontraban inmersos en el debate general del campo intelectual y literario del momento, pero adquirieron especial relevancia en el contexto del caso Padilla, pues su postura tuvo mucho más de continuidad que de abandono a un ideal. Su actuación estuvo cimentada menos en el carácter ideológico que en su concepción del escritor subversivo. Como anota Jorge Fornet, a diferencia de Julio Cortázar, Vargas Llosa optó por el enfrentamiento. "Su prestigio literario, su prestigio como parte del núcleo más selecto del boom, su cercanía a la Casa de las Américas y a la Revolución cubana, provocaron que la colisión resultara especialmente sonada" (Fornet 2013: 205).

El personaje principal de Conversación en La Catedral (1969), Zavalita, se preguntaba "¿En qué momento se había jodido el Perú?" (Vargas Llosa 1981: 13). La pregunta se convirtió en el hilo conductor de aquella novela, pero además consiguió pasar la frontera de lo literario para establecerse en un reparo obligado en el debate de la ciudad letrada latinoamericana. De alguna forma, Vargas Llosa se había adelantado al desencanto que permeó en no pocos intelectuales a inicios de 1970: para Zavalita, el mundo estaba jodido y no tenía solución. A decir de José Miguel Oviedo, Zavalita era un personaje "lleno de dudas, un inconforme a medias, paralizado para la acción. Su caso refleja desencanto y el vacío en los que se sumió la sociedad peruana" (Oviedo 2007: 329). El vacío y el desencanto se extendieron a otras esferas de la vida latinoamericana y se convirtieron 
en componentes estéticos que Vargas Llosa utilizó, con mayor énfasis a partir de entonces, en su narrativa. Zavalita se convertirá en un prototipo de intelectual del fracaso cuya figura será aún más desarrollada por el peruano en La guerra del fin del mundo (1981). Si en Conversación en La Catedral el panorama ya era desalentador, en La guerra del fin del mundo la atmósfera toma un tono fatalista, violento, lleno de conspiraciones y casi apocalíptico. Hay, además, una diferencia fundamental: el papel que se asigna al intelectual en uno y otro caso. En Conversación en La Catedral, la participación de Zavalita en la lucha contra la dictadura es por convicción, se asume como un militante de izquierda y desde esa posición política, aunque matizada por la ingenuidad de una primera incursión en el mundo de la militancia, enfrenta la vida en diferentes planos. Sin embargo, luego de los sucesos vividos, su visión del mundo reside en el escepticismo y el desencanto. En cambio, en La guerra del fin del mundo, el periodista de quien nunca se menciona el nombre -que tiene la necesidad de usar anteojos, con una postura distante, escéptica, como un observador que no termina de ver bien por una serie de condiciones físicas-, se encuentra involucrado de lleno en el conflicto narrado, más que por convencimiento de una causa, o luchando por un ideal, por razones inevitables de su profesión y del desarrollo de los acontecimientos que lo llevan a conocer, en carne propia, la violencia, el desamparo, en el poblado de Canudos. ${ }^{5}$ Para Liliana Weinberg, en esta obra el escribidor "asume una posición relativista" buscando que la novela se pareciera más a una crónica antes que a una evaluación, sin embargo la obra se convierte en realidad "en un juicio sobre los intelectuales, representados por el irlandés Gall y el periodista sin nombre" (Weinberg 2004: 214).

La guerra del fin del mundo es una construcción simbólica de la vida, es la visión de Vargas Llosa sobre lo inexplicable de la guerra y la violencia como males casi intrínsecos a la condición del ser humano. Además, los personajes reflexionan sobre el poder, el fanatismo religioso y

5 Para una caracterización de las contradicciones que Canudos representa, es de gran valía el ensayo de Eduardo E. Parrilla, "La búsqueda de la utopía y el conflicto ideológico en la novela de Vargas Llosa", 2010. 
político como sucede luego de una escaramuza entre el ejército brasileño y los seguidores del Consejero:

la lógica de los elegidos del Buen Jesús no era la de esta tierra. La guerra que ellos libraban era sólo en apariencia la del mundo exterior, la de uniformados contra andrajosos, la del litoral contra el interior, la del nuevo Brasil contra el Brasil tradicional. Todos los yagunzos eran conscientes de ser sólo fantoches de una guerra profunda, intemporal y eterna, la del bien y del mal que se venía librando desde el principio del tiempo (Vargas Llosa 1985: 88).

La violencia y el fanatismo que desatan la rebelión de los yagunzos aparecen en la novela del peruano como algo imposible de explicar. Ninguno de los personajes que se lo preguntan logra entender cómo y por qué la gente humilde de esa zona de Brasil pudo dar la vida por el Consejero; tampoco logran explicar la conversión de criminales en hombres luchando que se entregan a una causa "divina" que en Belo Monte encontrarían la expiación de sus pecados, la solidaridad, la fraternidad, el desapego a la riqueza e incluso, como ocurre con João Satán y Pajeú, el amor. El fenómeno de Canudos es inexplicable tanto para el periodista miope como para Galileo Gall, el frenólogo anarquista que ve en esa rebelión una manifestación de la lucha de clases y que hace todo lo posible por llegar hasta donde se halla Antonio Consejero.

Galileo Gall está convencido de la justeza de la sublevación sertanera, pero en su figura y sus actos hay dos elementos a cuestionar: $a$ ) su militancia anarquista lo hace ver en el fanatismo de los seguidores del Consejero una lucha contra la estructura de los poderosos -sus formas de gobierno, la abolición de la propiedad privada-, proyectando sus deseos donde la realidad era diferente. Desde su perspectiva "Su ceguera intelectual no le había permitido comprender que estos hermanos, con instinto certero, han orientado su rebeldía contra el enemigo nato de la libertad: el poder. [... han acertado también con el método, el único que tienen los explotados para romper sus cadenas: la fuerza" (Vargas Llosa 1985: 42 y 43); y b) pese a su entrega a las mejores causas del ser humano, ese anarquista sucumbe ante las pasiones más bajas del hombre que se manifiestan al cometer la violación sexual contra Jurema. El gesto es, por eso, una manera 
de señalar que ni siquiera alguien como él, entregado en alma y cuerpo a la lucha revolucionaria, preso varias veces por sus acciones militantes, se salva de esa violencia propia del hombre, de esa violencia irracional, bestial, animal.

La guerra del fin del mundo contiene un aluvión de meditaciones sobre el comportamiento humano, la intriga, la mentira, y lleva el desencanto hacia todas las esferas. Alguien como el Barón de Cañabrava, conmovido hasta la médula por la locura de su mujer luego de que les fueron arrebatadas sus propiedades, que demuestra su amor estando con ella, procurándole cuidados, no puede, sin embargo, evitar abusar sexualmente de Sebastiana, la dama de compañía de su esposa. Otro personaje como el joven Teotonio, médico militar, ve trastrocadas sus ideas de patriotismo, de entrega a la República, de amor a Brasil, "descubrió que muchos [soldados, oficiales] trataban de evitar la guerra mediante el pretexto de la mala salud. Los había visto inventar enfermedades, aprenderse los síntomas y recitarlos como consumados actores, para hacerse declarar inaptos" (Vargas Llosa 1985: 338). Además, la novela del escribidor señala que todo vale con tal de conservar el poder, no importa nada, ni siquiera el honor. El Barón de Cañabrava es categórico ante sus colegas y en su calidad de representante de la vieja estructura terrateniente del Brasil insta a sus compañeros a apoyar a la República y a Moreira César, el coronel que dirige la guerra contra los yagunzos, "Para defender los intereses de Bahía hay que seguir en el poder y para seguir en el poder hay que cambiar de política, al menos por el momento [...]. Es una mojiganga ridícula, pero no tenemos alternativa" (Vargas Llosa 1985: 129). Las palabras del Barón son de una claridad abrumadora porque en el fondo no hay convicciones de ninguna índole; lo único que importa es el poder y para conservarlo se debe hacer lo que sea necesario.

Lo que sucede en la historia de Canudos es visto a través de los espejuelos del periodista que, además, escribe primero según se lo solicita Epaminondas Gonçalves, figura del republicanismo, y luego, casi al final de la historia, pretende dar testimonio de lo sucedido en Belo Monte con financiamiento del Barón de Cañabrava, rival de aquél. El periodista le confiesa a Gonçalves, "No sé qué soy, señor [...]. No tengo ideas politi- 
cas, ni me interesa la política" (Vargas Llosa 1985: 108; las cursivas son mías). Asimismo, en todo el entramado está presente la perspectiva de los militares hacia la labor de los intelectuales, según Moreira César "Todos los intelectuales son peligrosos [...]. Débiles, sentimentales, y capaces de usar las mejores ideas para justificar bribonadas. El país los necesita, pero debe manejarlos como animales que hacen extraños" (Vargas Llosa 1985: 163; las cursivas son mías). El intelectual es, en otras palabras, solamente un títere cuya función está determinada por el poder político y se reduce a "justificar bribonadas".

Al periodista miope, en más de una ocasión, lo acechan el escepticismo y las dudas sobre la rebelión que develan su incapacidad para obtener una explicación sobre las mismas, "Se trata de algo más difuso, inactual, desacostumbrado, algo que su escepticismo le impide llamar divino o diabólico o simplemente espiritual" (Vargas Llosa 1985: 197). Luego, entre las muchas complicaciones que vive cubriendo la guerra, su tablero y sus plumas quedan hechos pedazos, queda desarmado y piensa, refiriéndose a los soldados de la campaña, "será terrible. Algo que nunca podrá reproducir fielmente por escrito. Piensa: están llenos de odio, intoxicados por el deseo de venganza" (Vargas Llosa 1985: 219). La imagen del periodista no puede ser peor: está prácticamente sin visión, timorato, incapaz de ningún compromiso o convicción y, por si fuera poco, sus herramientas de trabajo, lo mismo que sus esperanzas, quedan hechas trizas. Cuando el periodista se entrevista con el Barón de Cañabrava, al contarle lo que vivió en Canudos, asegura: "En realidad no vi nada [...] se me rompieron los anteojos el día que deshicieron el Séptimo Regimiento. Estuve allí cuatro meses viendo sombras, bultos, fantasmas" (Vargas Llosa 1985: 268). Sin sus anteojos, se queda en completa oscuridad, ciego; imposibilitado de ver y de entender, el miedo se apodera de él y se considera "el hombre más cobarde del mundo", además "pese a sus travesuras bohemias, el opio, y al éter y a los candomblés, era alguien ingenuo y angelical. No era extraño, solía darse entre intelectuales y artistas. Canudos lo había cambiado, por supuesto. ¿Qué había hecho de él? ¿Un amargado? ¿Un escéptico? ¿Acaso un fanático?" (Vargas Llosa 1985: 313) (las cursivas son mías). El miope confiesa: "Gracias a Canudos tengo un concepto muy po- 
bre de mí mismo" (Vargas Llosa 1985: 318). Al estar entre los yagunzos, con esos desharrapados, con los heridos y los muertos ocasionados por la guerra, el periodista piensa que "Él también era un monstruo, un tullido, inválido, anormal. No era accidente que estuviera donde han venido a congregarse los tullidos, los desgraciados, los anormales, los sufridos del mundo. Era inevitable pues era uno de ellos" (Vargas Llosa 1985: 360). De esta forma, el escepticismo alcanza también la construcción narrativa de Vargas Llosa: a través de la edificación de un personaje que no puede ver, y de la necesaria parcialidad de todo testigo, aun el más inteligente y el más sensible, se pregunta con escepticismo sobre la omnipotencia de un autor comprometido.

El momento cumbre de reflexión del periodista sobre sí mismo, sobre su preparación intelectual y su profesión, ocurre cuando sostiene una breve conversación con el León de Natuba, uno de los personajes miembros del séquito del Consejero. La característica principal del León es que, dentro de Belo Monte, en el grupo de rebeldes, era de los pocos que sabía leer y escribir; era, en cierto sentido, el intelectual de los yagunzos:

-He leído el Misal abreviado y Las Horas Marianas muchas veces. Y todas las revistas y papeles que la gente me traía de regalo, antes. Muchas veces. ¿El señor ha leído mucho también? [...].

-He leído algunos libros -repuso, avergonzado-. Y pensó: "No me ha servido de nada". Era una cosa que había descubierto en estos meses: la cultura, el conocimiento, mentira, lastres vendas. Tantas lecturas y no le babian valido de nada para escapar, para librarse de esta trampa.

-Sé que es la electricidad -dijo el León de Natuba, con orgullo-. Si el señor quiere, se lo puedo enseñar. Y el señor, a cambio, me puede enseñar cosas que yo no sepa. Sé qué es el principio o ley de Arquímedes. Cómo se momifican los cuerpos. Las distancias que hay entre los astros [...].

¿Por qué lo desazonaba tanto alguien que sólo quería hablar, qué desplegaba así sus cualidades, sus virtudes, para ganar su simpatía? "Porque me parezco a él-pensó- porque estoy en la misma cadena de la que él es el eslabón más degradado" (Vargas Llosa 1985: 364 y 365 ) (las cursivas son mías).

Es cierto, como señala José Miguel Oviedo, que La guerra del fin del mundo es un "vasto cuadro, de proporciones épicas, que reconstruye libremente hechos del pasado histórico brasileño para reflexionar sobre 
cuestiones vivas hoy: el fanatismo ideológico, el papel de los intelectuales y los políticos, la violencia, la religión y el cambio" (Oviedo 2007: 339). Sin embargo, la principal crítica está centrada en la figura del intelectual. No es casual que el periodista sea miope, desgarbado, débil; ni tampoco lo es que en los momentos más complicados de la guerra en Canudos se haya quedado completamente ciego; ni es fortuito que se considere a sí mismo como lo más "degradado". Si la fortaleza intelectual se basa en lo leído y en los análisis de las lecturas, ante la violenta realidad al miope no le había servido ni lo uno ni lo otro. El periodista funciona entonces como el personaje que proyecta la visión de Vargas Llosa hacia todos los intelectuales, es decir, es una dura crítica a su papel dentro de la sociedad por su incapacidad de entender ciertos fenómenos, por no poder explicar sucesos como los ocurridos en esa región del Brasil. Ante la realidad, parece señalar el peruano, el intelectual es débil e inútil, de nada le ha valido leer, ser culto, prepararse tanto. Hay, por eso mismo, en la construcción del personaje intelectual en la novela, un desencanto de su labor: entre más se enfrenta a la realidad social y política menos puede entenderla. $L a$ guerra del fin del mundo muestra un complejo entramado de descomposición del ser humano que el intelectual "revolucionario" o "crítico" es incapaz de explicar.

\section{CONSIDERACIONES FINALES}

El desencanto de Mario Vargas Llosa, reflexionado literariamente en $L a$ guerra del fin del mundo, es generalizado: muestra al ser humano decadente, sin futuro, sin horizonte y al intelectual como una figura que no sabe siquiera qué es: testigo apolítico de los acontecimientos, ciego e incapaz de dilucidar correctamente fenómenos como la violencia y el fanatismo. En contraparte Julio Cortázar, en Libro de Manuel, hace una férrea crítica a la izquierda, pero sin dejar de tomar partido por ella. Andrés y Lonstein sostienen una polémica constante con los militantes más comprometidos de la Joda. No es accidental que sean ellos dado que, por un lado, Lonstein es el menos serio de todos los personajes, el onanista, 
el adicto a los alucinógenos; por otro lado, Andrés es intelectualmente hablando el más preparado, culto y exquisito. Lo relevante es que uno y otro son, o quieren ser, parte de las operaciones de la Joda asumiendo los riesgos y los compromisos políticos que ello requiere. El desencanto en Cortázar no se revela del mismo modo que en Vargas Llosa, sino que se traduce en el compromiso por la libertad de los presos políticos y la soberanía de Latinoamérica, pero sin que ello significara la cancelación de la libertad intelectual y artística; sin que ello fuese un impedimento para lo lúdico y divertido de la creación artística y para que, en suma, la propia izquierda tomara en cuenta tales elementos, los hiciera suyos y se permitiera ser menos dogmática. Si en La guerra del fin del mundo el intelectual es miope y débil, en Libro de Manuel es juguetón, enamoradizo, extremadamente crítico de sus compañeros; si en la novela del peruano el periodista no puede ver, y se caracteriza a sí mismo como lo más degradado, en la historia del argentino, Andrés está convencido de que el camino es el de la izquierda, pero no de aquella que, en nombre de su proyecto y objetivos, cancele la posibilidad de lo lúdico, la alegría y la irreverencia. Las tres novelas analizadas sucintamente son, en conjunto, testimonio de una diáspora del desencanto que, sin embargo, tiene al intelectual como un protagonista esencial. Julio, el escritor de En mi jardín pastan los béroes, el periodista miope de Vargas Llosa y el Andrés de Cortázar son tres proposiciones artísticas distintas de una misma preocupación: la labor del intelectual y el artista en los procesos políticos. Las visiones que reflejan son, en buena medida, las discusiones por las que atravesaba el espacio intelectual latinoamericano luego del Caso Padilla que ocasionó el repensar el papel del intelectual. Heberto Padilla traduce ese desencanto señalando que el intelectual, en una sociedad como la que estaba construyendo la Revolución cubana, "tiene que tragar sapos vivos", porque "toda la vida nos acompañará una imborrable sensación de asco. Asco a las ilusiones" (Padilla 1989: 108). Su desencanto encuentra fundamento, indudablemente, en la experiencia vivida por él y otros escritores para quienes la Revolución en su país dejó de significar un proyecto, una esperanza, un horizonte. No es que renunciara a tener fe en su profesión, pero desde su perspectiva ya no había cabida para ella en el proyecto 
socialista cubano. Desde su punto de vista, una inteligencia crítica, como la de Julio en la novela, no era pertinente para el rumbo que el proceso cubano había tomado.

Mientras tanto, la obra de Vargas Llosa cuestiona mordazmente al intelectual en todos sus aspectos. La guerra del fin del mundo, además de inaugurar una nueva etapa en la narrativa del escribidor, en la que, a decir de Carmen Perilli, "cambia su concepción social y su proyecto estético" (Perilli 2010: 74) es fiel muestra del desencanto y la desesperanza política. En la perspectiva de Vargas Llosa, el intelectual está condenado a enfrentarse solo a la realidad social y, peor aún, se encuentra destinado a la incomprensión de ésta, a fracasar al intentar formarse una explicación de fenómenos como la violencia, el poder, el fanatismo y el autoritarismo.

Si bien Libro de Manuel es la novela política de Cortázar que da testimonio del cronopio comprometido con las luchas de izquierda en América Latina, resulta significativo el hecho de que centre sus críticas a los intelectuales y los dirigentes revolucionarios. Cortázar debatía contra las concepciones rígidas de la izquierda latinoamericana que, como ocurría en Cuba durante el quinquenio gris, concebían al arte solo en función de su "utilidad" hacia las masas. Libro de Manuel es también el intento cortazariano de zanjar esa dicotomía entre el escritor y su compromiso político, pero con el acento puesto en su labor artística.

\section{BiBLIOGRAFÍA}

CASTRO, Fidel. "Declaración del carácter socialista de Cuba, 16 de abril de 1961". Artículo en línea disponible en www.cuba.cu/gobierno/discursos (consultado el 13 de enero de 2020).

Ceriant, Cecilia (1989). "No tengo ira', afirma el escritor cubano Heberto Padilla". Artículo en línea disponible en http://elpais.com.diario/1989/04/02/cultura (consultado el 1o. de septiembre de 2019).

COLlAZOS, ÓSCAR. "La encrucijada del lenguaje". Óscar Collazos, Julio Cortázar y Mario Vargas Llosa. Literatura en la revolución y revolución en la literatura. México: Siglo XXI, 1970. 7-37. 
CORTÁZAR, JULIO. "Literatura en la revolución y revolución en la literatura: algunos malentendidos a liquidar". Óscar Collazos, Julio Cortázar y Mario Vargas Llosa, Literatura en la revolución y revolución en la literatura, México: Siglo XXI, 1970: 38-77.

CORTÁZAR, Julio. Libro de Manuel. Madrid: Suma de Letras, 2004.

Donoso, José. Historia personal del boom. Santiago de Chile: Andrés Bello, 1987.

FORNET, JORGE. Los nuevos paradigmas: prólogo narrativo al siglo XXI. La Habana: Letras Cubanas, 2006.

FORNET, JORGE. El 71. Anatomía de una crisis. La Habana: Letras Cubanas, 2013.

FRANCO, JEAN. Decadencia y caída de la ciudad letrada. La literatura latinoamericana durante la Guerra Fría. Trad. Héctor Silva Míguez. Barcelona: Debate, 2003.

GarRAMUÑo, Florencia. La experiencia opaca. Literatura y desencanto. Buenos Aires: FCE, 2009.

GILMAN, CLAUDIA. Entre la pluma y el fusil. Debates y dilemas del escritor revolucionario en América Latina. Buenos Aires: Siglo XXI, 2003.

González Bermejo, ERnesto. Conversaciones con Cortázar. Barcelona: EDHASA, 1978.

HuneEus, Cristian. (1971). "Diálogo en La Habana. Entrevista a Heberto Padilla". Artículo en línea disponible en www.letras.55.com (consultado el 27 de octubre de 2019).

MaqueIRA, EnZo. Cortázar: De cronopios y compromisos. Buenos Aires: Longseller, 2002.

MARTÍNEZ PÉREZ, LILIANA. Los hijos de Saturno: intelectuales y revolución en Cuba. México: Flacso/Miguel Ángel Porrúa, 2006.

Oviedo, José Miguel. Historia de la literatura bispanoamericana, t. IV, de Borges al presente. Madrid: Alianza Editorial, 2001.

Oviedo, José Miguel. "Vargas Llosa, testigo del mundo". Dossier Vargas Llosa, Lima, Taurus, 2007.

PADIlLA, HeBerTo (1968). Fuera del juego. Artículo en línea disponible en http://circulodepoesia.com (consultado el 30 de agosto de 2019). 
PADILla, HeBerTo. En mi jardín pastan los héroes. Barcelona: Argos Vergara, 1981.

PADilla, HeberTo. La mala memoria. Barcelona: Plaza \& Janes, 1989.

Padilla, Heberto. "Autoconfesión". Casa de las Américas 65.66 (1971): 191-203.

PARRILla, EDUaRDo E. "La búsqueda de la utopía y el conflicto ideológico en la novela de Vargas Llosa". Pol Popovic Karc y Fidel Chávez Pérez (coords.). Mario Vargas Llosa: perspectivas críticas (ensayos inéditos), México: Instituto Tecnológico de Monterrey/Miguel Ángel Porrúa, 2010. 316-363.

PEREIRA, ARMANDO. Novela de la Revolución cubana (1960-1990), México: UNAM, 1995.

PERILLI, CARMEN. "Una ilustre familia: la reivindicación del autor en Mario Vargas Llosa”. Kanina Revista Artes y Letras XXXIV (2010): 73-84.

Peris Blanes, Jaume. "Libro de Manuel, de Julio Cortázar, entre la revolución política y la vanguardia estética". Cuadernos de Investigación Filológica 31.32 (2005-2006): 143-161.

PERIS Blanes, Jaume. "Cortázar: entre la cultura pulp y la denuncia política”. Estudios Filológicos 50 (2012): 95-112.

RAMA, ÁngEL. El "boom" en perspectiva. Buenos Aires: Folios Ediciones, 1984.

RAMA, ÁngEl. Diario 1974-1983. Montevideo: Ediciones Trilce, 2001.

RodríGuEZ MoneGal, EMir. "Tradición y renovación", César Fernández Moreno (coord. e introd.). América Latina en su literatura. México: Siglo XXI, 1982: 139-166.

SAFIR, MAGERY A. "Para un erotismo de la liberación: notas sobre el comportamiento transgresivo en Rayuela y Libro de Manuel". Jaime Alazraki, Ivar Ivask y Joaquín Marco (eds.). Julio Cortázar: la isla final. Barcelona: Ultramar, 1983: 223-252.

SOSNOWSKI, SAÚl (ed.). Julio Cortázar. Obra crítica 3. Madrid: Alfaguara, 1994.

VARGAS LLOSA, MARIO. Conversación en La Catedral. Barcelona: Seix Barral, 1981. 
VARGAS LLOSA, MARIO. La guerra del fin del mundo. México: Origen/Planeta, 1985.

VARGAS LLOSA, MARIO. (1967). "La literatura es fuego". Artículo en línea disponible en https://www.literaterra.com/mario_vargas_llosa/la_literatura_es_fuego/ (consultado el 22 de agosto de 2020).

VARGAS LLOSA, MARIO. ÓSCAR COLLAZOS. Julio Cortázar. Literatura en la revolución y revolución en la literatura. México: Siglo XXI, 1970: 78-93. UNEAC. "Declaración". (1968). Artículo en línea disponible http://circulodepoesia.com (consultado el 14 de enero de 2020).

YAÑEZ, SOFÍA. Desencanto y literatura (elementos para el análisis). Tesis de maestría. Ecuador: Universidad Andina Simón Bolívar, 1997.

WeINBERG, LILIANA. Literatura latinoamericana. Descolonizar la imaginación. México: UNAM-CCYDEL, 2004. 